\title{
The emotional effects of tooth loss: a preliminary quantitative study
}

\author{
D. M Davis, ${ }^{1}$ J. Fiske, ${ }^{2}$ B. Scott, ${ }^{3}$ and D. R. Radford, ${ }^{4}$
}

\begin{abstract}
Aim To establish how widespread the emotional effects of tooth loss are.

Method A questionnaire, distributed to 100 edentulous people undergoing routine prosthetic care in the Department of Prosthetic Dentistry at Guy's, King's and St Thomas' Dental Institute (GKT), was used to explore the emotional effects of tooth loss.

Results Ninety four people completed the questionnaire of whom 42 stated that they had experienced difficulties in accepting the loss of their teeth. In comparison with people who had no difficulties in accepting the situation, these people were: more likely to feel less confident about themselves; more likely to feel inhibited in carrying out everyday activities; and less able to accept the inevitable change in facial shape which occurs following the loss of teeth. Additionally, they took longer to come to terms with their tooth loss (All these differences were statistically significant). Just over three-quarters of the people who were unprepared for the loss of their teeth, felt that an explanation from the dentist prior to dental extractions would have helped.

Conclusion The impact that tooth loss can have on people and their lives should not be underestimated. In this study it affected $45 \%$ of the participants.
\end{abstract}

$T^{t}$ is well established that people with dentofacial abnormalities experience social consequences including greater degrees of social avoidance and being perceived as possessing negative personality characteristics. ${ }^{1}$ Even minor facial abnormalities can result in social stigma. ${ }^{2}$ Visible disfigurements are recognised as having a profound effect on individuals ${ }^{3}$ and, according to French, hidden impairments (such as total tooth loss) can cause an equal amount of stress. ${ }^{4}$ Indeed, people with facial disfigurement are among those people who are covered by the 1995 Disability Discrimination Act. ${ }^{5}$

While Bergendal acknowledged total tooth loss as a serious life event, ${ }^{6}$ and the impact of dental ill health on daily living is well recognised, ${ }^{7-10}$ it is only recently that attention has been paid to the emotional effects of tooth loss. A qualitative study into the emotional effects of total tooth loss revealed a wide range of reactions. ${ }^{11}$ The main themes identified in relation to tooth loss were: bereavement; loss of self confidence; concerns about appearance and self image; tooth loss as a taboo subject which could not be discussed with other people; keeping tooth loss secret; the need for prosthodontic privacy; behaviour change; premature ageing; and a lack of

\footnotetext{
${ }^{1,4}$ Senior Lecturer and Honorary Consultant, Department of Prosthetic Dentistry, Guy's, King's and St Thomas' Dental Institute, London; ${ }^{2}$ Senior Lecturer and Honorary Consultant, Department of Sedation and Special Care Dentistry, Guy's, King's and St Thomas' Dental Institute, London; ${ }^{3}$ Senior Lecturer and Honorary Consultant, Unit of Clinical Dental Sciences, Dental Hospital and School, Dundee Correspondence to: Dr David M Davis, Senior Lecturer and Honorary

Consultant, Department of Prosthetic Dentistry, Guy's, King's and St Thomas'

Dental Institute, Caldecot Road, Denmark Hill, London SE5 9RW

REFEREED PAPER

Received 26.07.99; accepted 11.01.00

(C) British Dental Journal 2000; 188: 503-506
}

preparation for the loss of teeth. A further qualitative study among people with partial tooth loss uncovered a similar pattern of emotional reactions. A feeling of having lost part of one's self was an additional finding in the partially dentate group. ${ }^{12}$

The researchers were surprised at the depth of feeling that existed among the participants of these two studies, particularly, as they were all coping apparently well with dentures. The subjective view was that these feelings were experienced by a significant proportion of edentulous and partially dentate people. The current study is designed to make the next step by taking a preliminary look at how many edentulous people experience the emotional effects of tooth loss.

\section{The aim}

The aim of the present study is to establish how widespread the emotional effects of tooth loss are by quantifying them.

\section{Method}

A questionnaire developed from the findings of the qualitative research ${ }^{11,12}$ was used as the basis for this quantitative study. The questionnaire contained 24 questions plus space for any additional comments that the participants wished to make about their experiences of losing teeth. The questionnaires were distributed randomly to 100 edentulous people attending the Department of Prosthetic Dentistry at Guy's, King's and St Thomas' Dental Institute (GKT). All the participants were receiving routine prosthetic care and were considered to be successful denture wearers.

Potential subjects were approached during the course of their treatment and, following an explanation of the purpose of the study, invited to take part. Few people declined to participate. Participants were given a questionnaire which they were asked to complete at home and then return by post in the stamped addressed envelope provided. The questionnaire and its process of distribution was piloted on a sample of 15 people recruited in the same manner as, but excluded from, the main study.

The data from the questionnaires were analysed using the chi squared $\left(\chi^{2}\right)$ test with Yates' continuity correction for $2 \times 2$ contingency tables in which expected frequencies were greater than five; and using Fisher's exact test ( 2 tailed) for $2 \times 2$ contingency tables in which expected frequencies were less than five. For all other analyses, the chi squared $\left(\chi^{2}\right)$ test was used. In the following text, the chi squared $\left(\chi^{2}\right)$ test with Yates' continuity correction has been used unless otherwise indicated.

\section{Results}

Ninety four people completed the questionnaire of whom 48 were male and 46 female. Seven of the participants were aged between 31 and 50 years, 40 between 51 and 70 years and 47 aged 71 years and over. Seventy people had been edentulous for more than 5 years. Ninety two of the participants were wearing complete dentures, while the remaining two people had recently been made edentulous and were in the process of having their first set of complete dentures made. 
Question: 'Did you find it difficult to accept losing your teeth?' Forty two of the respondents stated that they had experienced difficulties in accepting their tooth loss, which equates to $45 \%$ of the sample group. Fifty one people stated that they had experienced no difficulties, and one person stated that they did not know. On the basis of these findings, the data is presented, throughout the text, according to whether people found it difficult to accept the loss of their teeth or not. For clarity, the answers of the one person who was uncertain whether they had experienced any difficulties have been excluded from subsequent tables.

Question: 'How long was it before you felt you had accepted losing your teeth?' (Table 1)

People who highlighted difficulties in accepting tooth loss took significantly longer to come to terms with it compared with the people who did not express difficulties $\left(P<0.001, \chi^{2}\right.$ test $)$. Eighty four percent of the group with no difficulties accepted their loss immediately, whereas, $36 \%$ of the people with difficulties still had not accepted their loss at the time of the study.

Table 1 Time related to accepting tooth loss

\begin{tabular}{|c|c|c|}
\hline \multirow[t]{2}{*}{ Response } & \multicolumn{2}{|c|}{ Number of responses } \\
\hline & Difficulties & No difficulties \\
\hline Immediately & 2 & 43 \\
\hline Within 6 months & 5 & 7 \\
\hline Within a year & 4 & - \\
\hline Took over a year & 16 & 1 \\
\hline Still have not accepted it & 15 & - \\
\hline
\end{tabular}

Question: 'Thinking back to when you lost your last tooth, how did you feel?' (Table 2)

The over-riding emotion felt by individuals who had no difficulties accepting the loss of their teeth was one of relief ( 25 people). The only other emotions they related to with any frequency were resignation to the loss of their teeth and a lack of concern about that loss (12 and 15 people, respectively). The people who experienced difficulties expressed a wider and more complex range of emotions. Feelings of sadness and depression, having lost part of themselves, feeling old and a sense of resignation were the most commonly identified emotions $(21,16,17,15$, and 12 people, respectively). People in this group were more likely to select a number of responses compared with the group who had no difficulties. As the participants were asked to mark as many of the responses as they felt applied to them, statistical analysis of the data was inappropriate.

Table 2 Feelings associated with losing the last remaining tooth

\begin{tabular}{lcc}
\hline Response & \multicolumn{2}{c}{ Number of responses } \\
& Difficulties & No difficulties \\
\hline Relieved & 8 & 25 \\
Sad & 21 & 8 \\
Angry & 9 & 1 \\
Gloomy & 6 & 3 \\
Dismayed & 2 & 3 \\
Resigned & 12 & 12 \\
Depressed & 16 & - \\
Old & 15 & 2 \\
Not happening to me & 7 & - \\
Lost part of myself & 17 & 1 \\
Unconcerned & - & 15 \\
\hline
\end{tabular}

Question: 'Did losing your teeth affect your self-confidence'? (Table 3)

People who experienced difficulties accepting tooth loss felt much less confident about themselves than did the people without difficulties (69\% and 20\%, respectively). The majority of people who had no difficulties felt that their confidence was unaffected $(61 \%)$. There was a significant association between the ability to accept tooth loss and self confidence $\left(P<0.001, \chi^{2}\right.$ test). The people who answered do not know to this question were omitted from the statistical analysis.

Table 3 Tooth loss and self confidence

\begin{tabular}{|c|c|c|}
\hline \multirow[t]{2}{*}{ Response } & \multicolumn{2}{|c|}{ Number of responses } \\
\hline & Difficulties & No difficulties \\
\hline More confident & 1 & 9 \\
\hline Confidence unaffected & 9 & 31 \\
\hline Less confident & 29 & 10 \\
\hline Don't know & 3 & 1 \\
\hline
\end{tabular}

Question: 'Because of losing your teeth, have you ever been restricted in carrying out any of the following range of activities?' (Table 4)

People were asked to answer yes or no to each of six statements in this question. It should be noted that not everybody responded to each question. Members in both groups had been forced to restrict their choices of food. However, the group who experienced difficulties in accepting tooth loss felt more disadvantaged over a wider range of activities than the group with no difficulties. Seventy six per cent restricted their choice of food; $76 \%$ did not enjoy their food as much; $67 \%$ avoided eating in public; $62 \%$ avoided laughing in public; $34 \%$ avoided going out in public; and $52 \%$ avoided forming close relationships as a consequence of losing their teeth. The differences between those respondents with difficulties and those with no difficulties proved to be statistically significant for restricting the choice of food $(P=0.001)$; avoiding eating in public $(P<0.001)$; not enjoying food as much $(P<0.001)$; avoiding laughing in public $(P<$ $0.001)$; avoiding going out in public $(P<0.001$ Fisher's exact test $)$; and avoiding forming close relationships $(P<0.001)$.

Table 4 Activities restricted caused by tooth loss

\begin{tabular}{|c|c|c|c|c|}
\hline \multirow[t]{3}{*}{ Statement } & \multicolumn{4}{|c|}{ Number of responses } \\
\hline & \multicolumn{2}{|c|}{ Difficulties } & \multicolumn{2}{|c|}{ No difficulties } \\
\hline & Yes & No & Yes & No \\
\hline Choice of food restricted & 29 & 9 & 18 & 31 \\
\hline Avoid going out in public & 10 & 19 & 1 & 44 \\
\hline Avoid eating in public & 22 & 11 & 4 & 42 \\
\hline Not enjoyed food as much & 29 & 9 & 14 & 31 \\
\hline Avoid laughing in public & 21 & 13 & 3 & 42 \\
\hline Avoid forming close relationships & 16 & 15 & 3 & 40 \\
\hline
\end{tabular}

Question: 'Do you think that the shape of your face has changed since you lost your teeth?'

People who had difficulties accepting the loss of their teeth were more likely to feel that the shape of their face had changed as a result of losing their teeth (83\% of people compared with 59\%). In addition, this group was more likely to be upset by the change $(69 \%$ compared with $23 \%$ ). On the whole, the group without difficulties was unconcerned by the change and this difference was statistically significant $\left(P=0.001, \chi^{2}\right.$ test $)$.

Question: 'Do you ever avoid looking at yourself, letting your partner see you, or letting friends see you without your dentures in place?'

Fifty per cent of people with difficulties accepting tooth loss avoided looking at themselves without their dentures in place compared with $24 \%$ of people without difficulties. This difference was statistically significant $(P=0.027)$. Sixty seven percent of people with 
problems and 34\% without problems avoided letting their partners see them without their dentures in place and again this difference was statistically significant $(P=0.009)$. The majority of people in both groups did not wish to be seen without their dentures by friends ( $86 \%$ and $75 \%$, respectively) and no statistical difference was observed $(P=0.316)$.

Question: 'Do you consider your dentures to be part of yourself, a foreign body, or neither of these?' (Table 5)

Ninety per cent of people in the group with no difficulties felt their dentures to be part of themselves. While the answers were more diverse in the group with difficulties, only $45 \%$ of them considered their dentures to be part of themselves. This difference was statistically significant $\left(P<0.001, \chi^{2}\right.$ test $)$.

Table 5 Perception of dentures related to self

\begin{tabular}{lcc}
\hline Response & \multicolumn{2}{c}{ Number of responses } \\
& Difficulties & No difficulties \\
\hline & & \\
Part of myself & 19 & 43 \\
A foreign body & 16 & 2 \\
Neither of these & 7 & 3 \\
\hline
\end{tabular}

Question: 'Did you feel prepared for the effect that the loss of your teeth had on you?'

Of the 94 people who took part in this study, 42 (45\%) felt unprepared for the effects of tooth loss. Seventy four per cent of people in the group who experienced difficulties and $22 \%$ of the group without difficulties felt that they had been unprepared. This difference was statistically significant $(P<0.001)$.

Question: 'Which of the following would have helped prepare you: a video about the effects of tooth loss; a leaflet about tooth loss; an explanation from the dentist; talking to someone who had already experienced tooth loss'?

Only people who felt unprepared for the effects of tooth loss were requested to answer this question and they were asked to select as many responses as they felt appropriate. Thirty three of the 42 people eligible to answer felt that an explanation from the dentist would have helped. Nineteen of them would have appreciated the opportunity to talk to someone who had experienced tooth loss; 14 people would have valued a pre-operative video on the possible effects of tooth loss; and 13 would have liked written information in the form of a leaflet.

\section{Discussion}

\section{Critique of method}

When designing a questionnaire, there is always a danger that the questions contained in it reflect the bias of the researchers and not the feelings of the participants. The questionnaire used in this study was based on the views expressed by the 50 edentulous people who took part in the previous qualitative study. Thus, the authors feel confident that it reflects the attitudes, needs and feelings of people who have lost all their teeth. Also, $67 \%$ of the participants took the opportunity to add additional comments to the questionnaire about their experiences of losing teeth which echoed the themes found in the qualitative study. This suggests that the questionnaire reflects the views of the participants.

All questionnaires are subject to the halo effect ie that the respondents will provide the answers that they think the researchers want. To minimise this effect, participants were instructed to take the questionnaire home to complete at their leisure in familiar surroundings. Also, this process helps to maintain anonymity and, thus, encourages people to express their own views.
It could be argued that a group of people being treated within a dental school is more likely to contain difficult denture patients and, therefore, is more likely to have difficulties in accepting the loss of their teeth compared with a group of people being treated in a general dental practice. In reality, the dental school in question is used by many people for routine care. Also, as the initial, qualitative study took place in a dental school, it was considered appropriate for the initial phase of the quantitative study to be conducted in a similar environment. Further work is planned to widen the sample and to encompass different environments in both the dental and non-dental fields.

\section{Emotional reactions to tooth loss}

People's reactions to the loss of their teeth is likely to be affected by their ability to wear dentures. This is to some extent borne out by the fact that $90 \%$ of people in the group with no difficulties felt that their dentures were part of themselves. However, the fact that $45 \%$ of the people with difficulties felt their dentures to be a part of themselves clearly shows that, while dissatisfaction with dentures will play a part in people's reactions to tooth loss, it does not account for the whole picture.

It is clear from the results that the loss of teeth can have a dramatic impact on the lives of some people. Forty five per cent of participants experienced difficulties in accepting the loss of their teeth. In comparison with people who had no difficulties accepting the situation, these people are more likely to feel less confident about themselves and are more likely to feel inhibited in carrying out a range of activities. They are also less able to accept the inevitable change in facial shape which occurs following the loss of teeth. In addition, they take longer to come to terms with their tooth loss. Indeed 36\% of them failed to come to terms with their loss at all. This study indicates that the effect of tooth loss on self esteem and self image is not as short lived as has, perhaps, been assumed. It is possible that some of the problems presented to dentists by 'difficult denture patients' stem from the emotional effects of tooth loss rather than from the dentures to which the patients attribute their problems.

The reason people avoid looking at themselves without their dentures is related to the avoidance of reinforcing the associated facial changes and emotions of tooth loss. ${ }^{4}$ Therefore, it is not surprising that people who had difficulties accepting the loss of their teeth were more likely to avoid looking at themselves without their dentures than the people who had no difficulties. The same applied to letting partners see them. However, neither group felt comfortable about letting friends see them without teeth.

\section{Preparing for tooth loss}

The fact that $45 \%$ of the people in this study felt unprepared for the effect that the loss of their teeth would have on them, clearly indicates that people believe the dental profession is not doing all that it can to explain the effects of tooth loss. It is of note that $22 \%$ of the people, who had no difficulties accepting the loss of their teeth, still felt unprepared for the effects of tooth loss. Accepting tooth loss does not automatically equate with being prepared for the consequences. Just over three-quarters of the people, who were unprepared, felt that an explanation from the dentist would have helped. It is, of course, quite possible that an explanation was given, but whether patients hear, or listen to, what is said is another matter. They may not hear because of anxiety about the impending extractions. ${ }^{13}$ Alternatively, they may not hear because they do not want to believe the possible effects of tooth loss. ${ }^{13}$ On both counts, it is advisable to provide the information about tooth loss at an appointment, or appointments, prior to the extraction day. It would also seem wise to link the explanation with one of the other options (which were suggested by people in the previous qualitative study) - that is a video, a leaflet or the opportunity to talk to someone who has been in a similar situation. Allowing time to absorb 
the information and to consider the consequences of tooth loss helps people to prepare emotionally for the event, as well as being in accordance with good practice in obtaining informed consent.

The extent of the impact that bad news, such as having to lose teeth, has on an individual is most often dependent on the way in which the information is communicated. ${ }^{13}$ Thus, it is important that dentists should be flexible in their approach to discussing the possible impact of tooth loss, and not rely on just one approach. Clearly, some people will need little or no explanation, while others will require a much more detailed discussion, with the information being presented in more than one way.

\section{Conclusions}

Forty five per cent of the edentulous people in this study felt they had difficulties in coming to terms with the loss of their teeth. The impact that tooth loss can have on people and their lives should not be under-estimated.

The authors wish to thank DrJ T Newton for his help with the questionnaire design, a copy of which can be obtained by writing to the address for correspondence.
1 Newton J T, Fiske J, Foote O, Frances C, Loh I, Radford D R. A preliminary study of the impact of loss of part of the face and its prosthetic restoration. J Pros Dent, 1999; 82:585-590.

2 McGrouther D A. Facial disfigurement: The last bastion of discrimination. Br Med J 1997; 134: 991 only.

3 Salter M (Ed) Altered body image - the nurse role. London: John Wiley \& Sons Ltd, 1988.

4 French S. On Equal Terms: Working with Disabled People. Oxford: Butterworth Heinemann, 1988.

5 Disability Discrimination Act 1995. Book no: 0105450952 London: The Stationery Office.

6 Bergendal B. The relative importance of tooth loss and denture wearing in Swedish adults. Community Dent Health 1989; 6: 103-111.

7 Locker D. The burden of oral disorders in a population of older adults. Community Dent Health 1992; 9: 109-124.

8 Slade G D, Spencer A J. Development and evaluation of the oral health impact profile. Community Dent Health 1994; 11: 3-11.

9 Leao A, Sheiham A. The development of a socio-dental measure of dental impacts on daily living. Community Dent Health 1995; 13: 22-26.

10 Fletcher A M. Denturism must be resisted. Probe 1991; 33: 11 only.

11 Fiske J, Davis D M, Frances C, Gelbier S. The emotional effects of tooth loss in edentulous people. Br Dent J 1998; 184: 90-93.

12 Fiske J, Davis D M, Frances C, Gelbier S. The emotional effects of tooth loss. The Proceedings of the European Prosthodontic Association 1997; $21: 24$ (abs).

13 Newton J T, Fiske J. Breaking bad news: a guide for healthcare professionals. Br Dent J 1999; 186: 278-281. 